program called GOD, they first generate a biota, the phylogenetic lineages of which obey specified rules. Subsets of the "mainland biota" then colonize archipelagoes according to a program called WALLACE, and competition may or may not be introduced as a structuring influence. Unlike field workers, Colwell and Winkler know whether or not their effects. The interesting and somewhat discomfiting conclusion is that many of the neutral model approaches used in studies of real communities often fail to distinthough competition had been included in their program. There are several reasons for this difficulty in detecting "the ghost of competition past", the most important of them being that those species most vulnerable to competitive exclusion are already likely to have been lost from the biota of the entire archipelago. The search for more appropriate neutral models is a major task for the future.

Several of the authors in Ecological Communities, notably Brown and Bowers, emphasize that the identification of an apparent pattern and its subsequent comparison with appropriate neutral models should only be the first step. As a result of such analysis, a causal mechanism should be suggested and subjected to experimental testing. Certainly, experiments with real communities are difficult, but they have often helped to determine whether competition (discussed in detail by Brown and Bowers, among others), predation (Dayton), facilitation (Seifert) or stochastic processes (Sale) may communities are structured by competitive guish any effect of competition even

be influencing community structure.

Another message that emerges clearly from the book is that some communities are far from being saturated with species this alone will limit the general importance of competitive interactions. Both Lawton, in his important work on the insect communities on bracken, and Price, who considers fish parasites, demonstrate the occurrence of "empty niches" in communities.

Robert May, in the opening chapter, questions whether the various themes and approaches are leading us towards a resolution of the factors determining community structure. There is still a long way to go, but Ecological Communities must be considered to be a significant landmark on that road. A consensus is emerging (despite the rather vituperative exchanges, recorded here, between Gilpin and Diamond on the one hand and Connor and Simberloff on the other) and the book signals the general acceptance of the need to look critically at the nature of the evidence at our disposal and to give equal weight to the testing of all conceivable hypotheses, not just the one we happen to favour. At present, no one should claim too much. But we can look forward to a gradual emergence of understanding of the types of communities and environments in which particular species interactions are influential, and those in which such interactions are weak, intermittent or nonexistent but where, instead, disturbance and stochastic processes predominate.

C.R. Townsend is a Lecturer in the School of Biological Sciences, University of East Anglia.

\section{Counsel for chemists}

\section{Robert M. Joyce}

Guide to the Chemical Industry:

Technology, R \& D, Marketing, and

Employment.

By William S. Emerson.

Wiley: 1984. Pp.330. £35, \$40.25.

Problem Solving in the Chemical

Industry.

By R.J. Casey and M.J. Frazer.

Pitman: 1984. Pp.122. Pbk £8.95.

How does a chemistry student assess career opportunities in industry? Few members of university faculties have had enough industrial experience to be helpful, and friends who have recently gone to industry will have seen only a small part of the picture.

In his career counselling guide, W.S. Emerson describes what the chemical industry does and how, the roles of chemists and chemical engineers in industrial research and development, and the career opportunities that may occur. Although it addresses primarily only the development, manufacture and marketing of organic chemicals, the general principles concerned are applicable to any part of the chemical industry. And while the reader should be able to understand organic structures in order to follow much of the discussion, the style is easy to read and the few errors are not significant.

The author begins with a tour through the principal types of products manufactured in the organic chemical industry, with descriptions of their syntheses, and then moves sequentially through the research discovery, the identification of a potential new product or process, its development and commercialization. The types of industrial research - offensive and defensive - are described, emphasizing that research produces scientific knowledge, not products or processes.

Students should learn that the development of a laboratory discovery is not just a matter of turning it over to some engineers who will simply scale up the procedure. In the 1930 s, E.K. Bolton, director of Du Pont's Central Research Department, decided that the nylon his organization would develop must be 66 , which could be based on plentiful benzene, rather than 510 , which needed castor oil as a raw material. In doing so, he ignored the opinion of his technical experts that 66 was too intractable, and told them to find out how to make and spin it. They did - fortunately for Du Pont, because IG Farbenindustrie was close behind with 6 nylon, which could be made from benzene. The Guide provides case-histories of several developments that were similarly influenced by the technical and economic decisions that must constantly be made as a project proceeds.

Chapters on patents and on unit operations introduce students to subjects that are rarely covered in chemistry curricula. A section on management and marketing gives them glimpses of typical company organizations and of the activities of managers and marketing people, the latter very briefly. This section includes a chapter on reports, which is simply descriptive; one wishes that here the author had taken the opportunity to drive home to students the critical importance of good writing.

The description of career opportunities runs the gamut, with one to two paragraphs on each. And finally, how to get a job. As Emerson points out, selling oneself is the secret to getting a job and to advancing in the organization. In all the author has done well in meeting his aims, and his Guide will be worth the time of any college chemistry student who wants to learn something about the chemical industry.

The same cannot be said of Problem Solving in the Chemical Industry. After an extended review of the philosophy of problem solving (which includes no chemistry), eight case-histories of chemical problems are presented. The emphasis is on technique: definition of the problem, exploration of various approaches, discarding unpromising ones and arriving at a solution.

However, some of the solutions only define further problems. The case-history on electrowinning of uranium covers in considerable detail seven years of the development of a pilot plant process that was then shelved for economic reasons, leaving one to wonder whether the problem to be solved had been adequately defined. The solution to the problem of disposing of dichromate-sulphuric acid cleaning solution is to me self-evident without considering the alternatives discussed. There are no exercises or problems for the student, and altogether it is rather hard to see who would benefit from reading this book.

Robert $M$. Joyce, now retired, was formerly a Research Director for E.I. du Pont de Nemours, Wilmington, Delaware.

The two volumes in the Scientific American Library reviewed in Nature on 15 November (Constructing the Universe and The Second $L a w)$ are in Britain generally available through bookshops. Publisher is W. H. Freeman, prices are $£ 15.95$ and $£ 16.50$ respectively. 